\title{
POSITIVE PREDICTIVE VALUE OF PROSTATE FUSION BIOPSY
}

\author{
PROSCA 2019
}

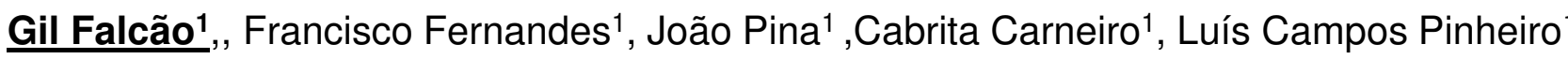
${ }^{1}$ Urology Department from Centro Hospitalar Universitário de Lisboa Central

\section{INTRODUCTION:}

- Prostate cancer is the most frequently diagnosed cancer

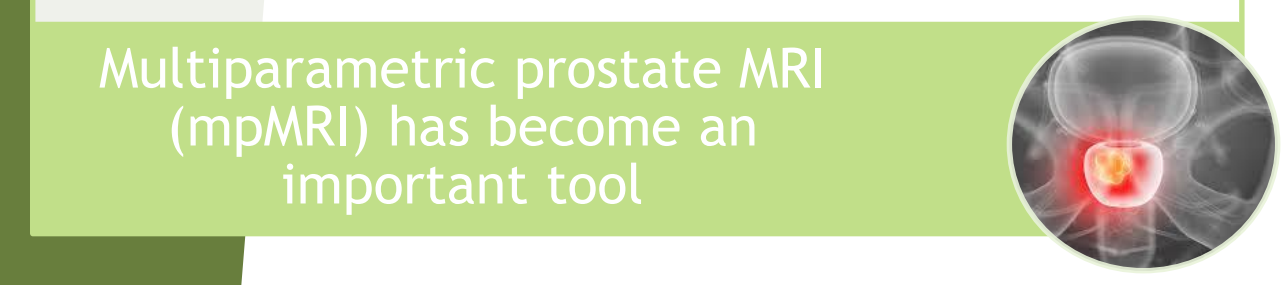

\section{OBJECTIVES:}

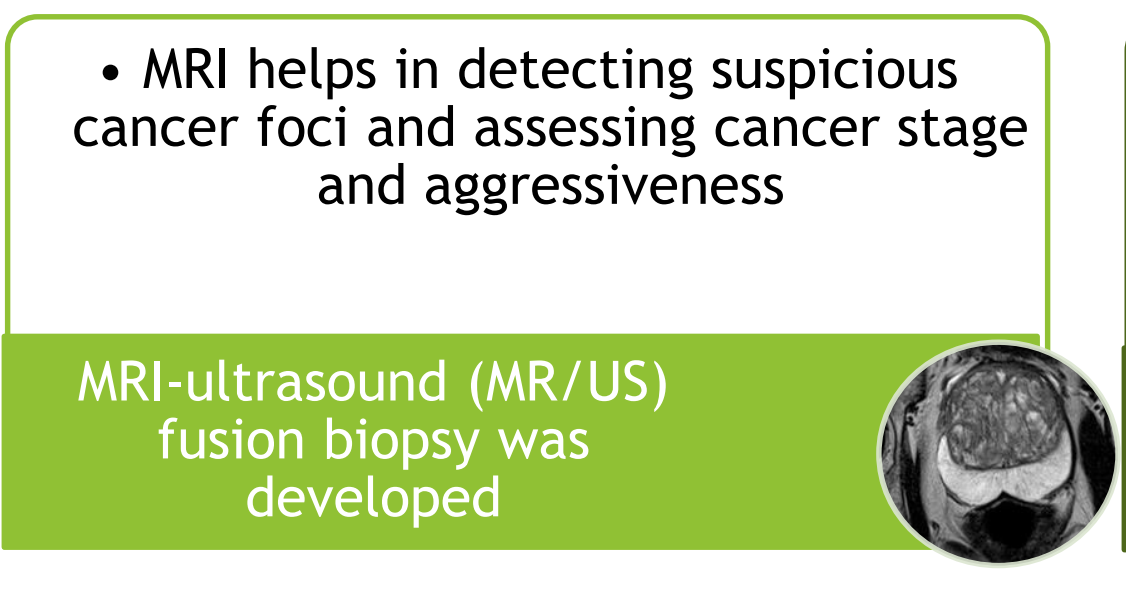

- The European Society of Urogenital Radiology published the Prostate Imaging Reporting and Data System (PI-RADS)

Clinically significant cancer lesions visualized on prostate MRI into five categories.

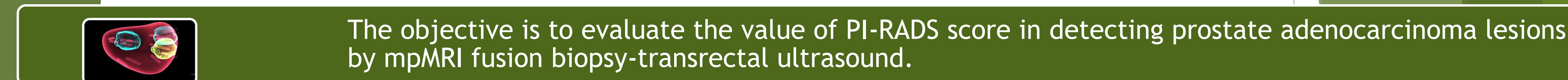

\section{MATERIAL/METHODS:}

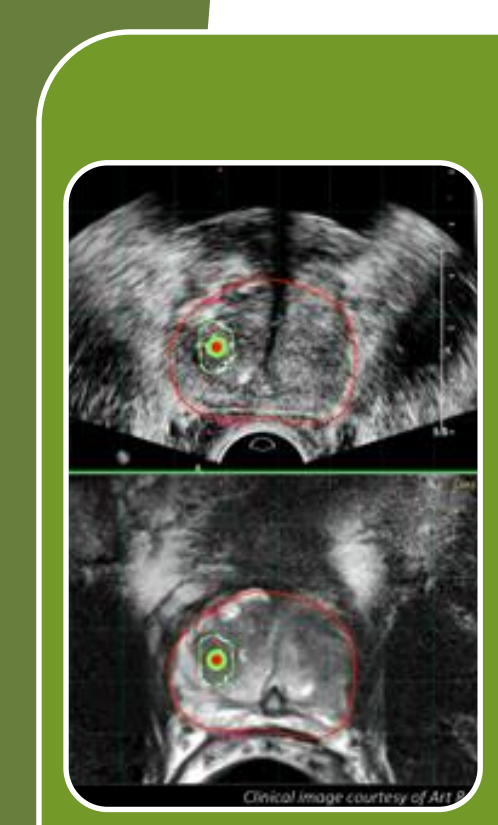

-Retrospective study

$-2015-2018$

-157 patients underwent fusion biopsy

$\approx 65$ years old

-353 PIRADS lesions between 3 and 5 were biopsied

On average, 5 fragments were removed per suspected zone

- PI-RADS scores were correlated with biopsy results and their calculated positive predictive values

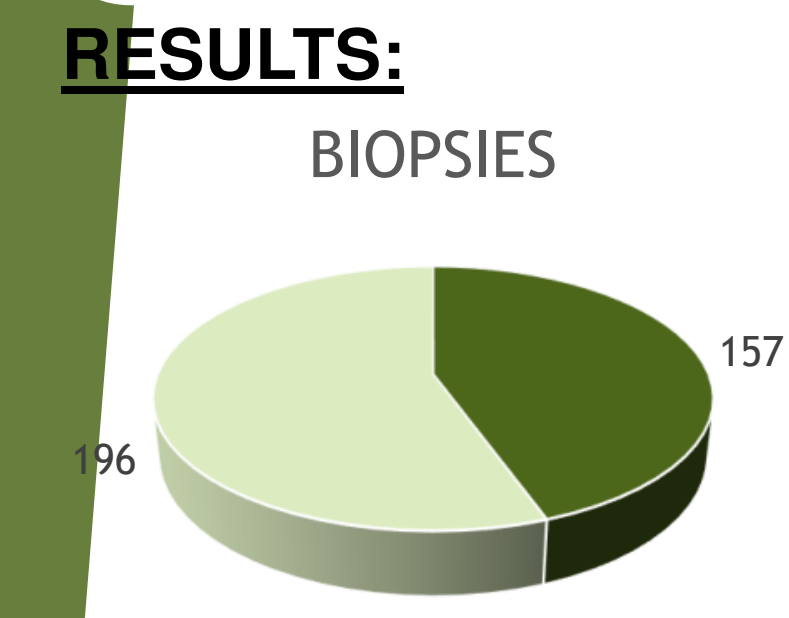

- Positive - Negative

PI-RADS 4

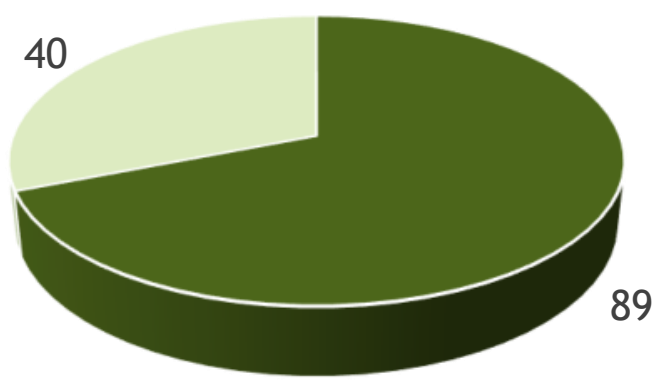

- Positive Negative
PI-RADS 3

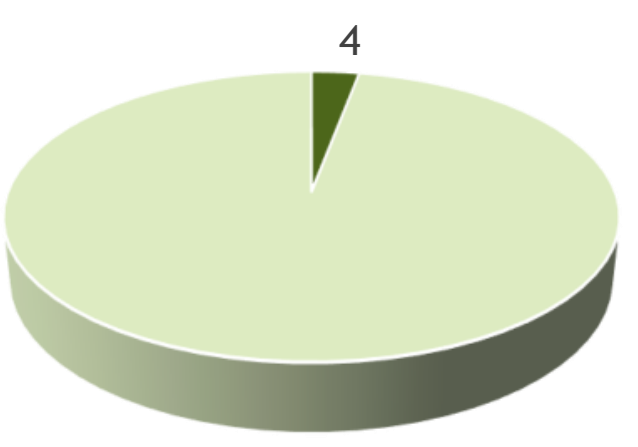

132

- Positive Negative

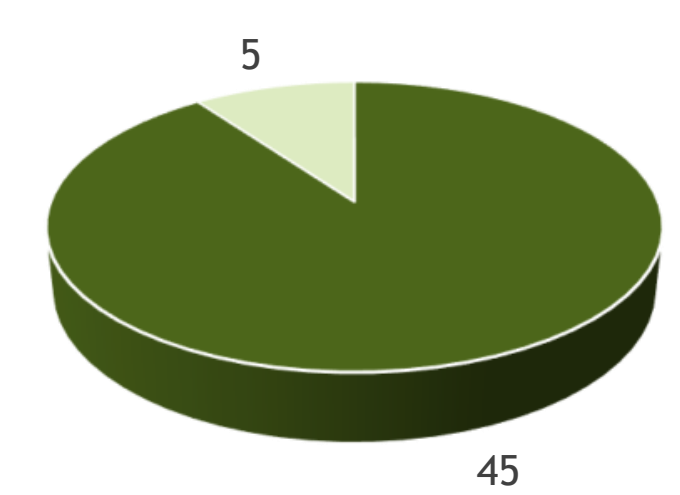

- Positive Negative

\section{By Gleason $>6$}

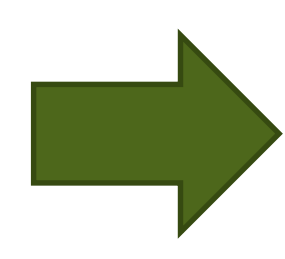

PI-RADS 4

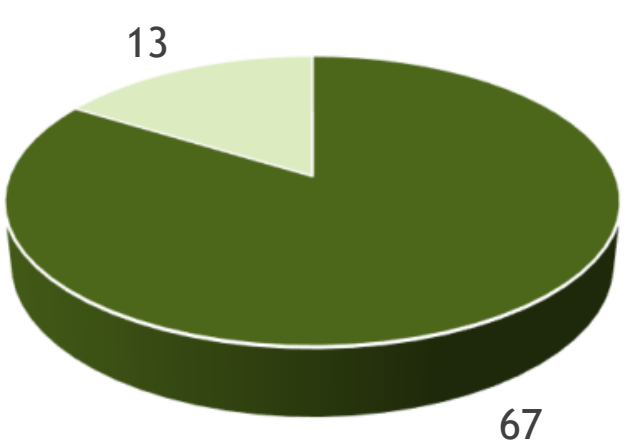

- Positive $\backsim$ Negative
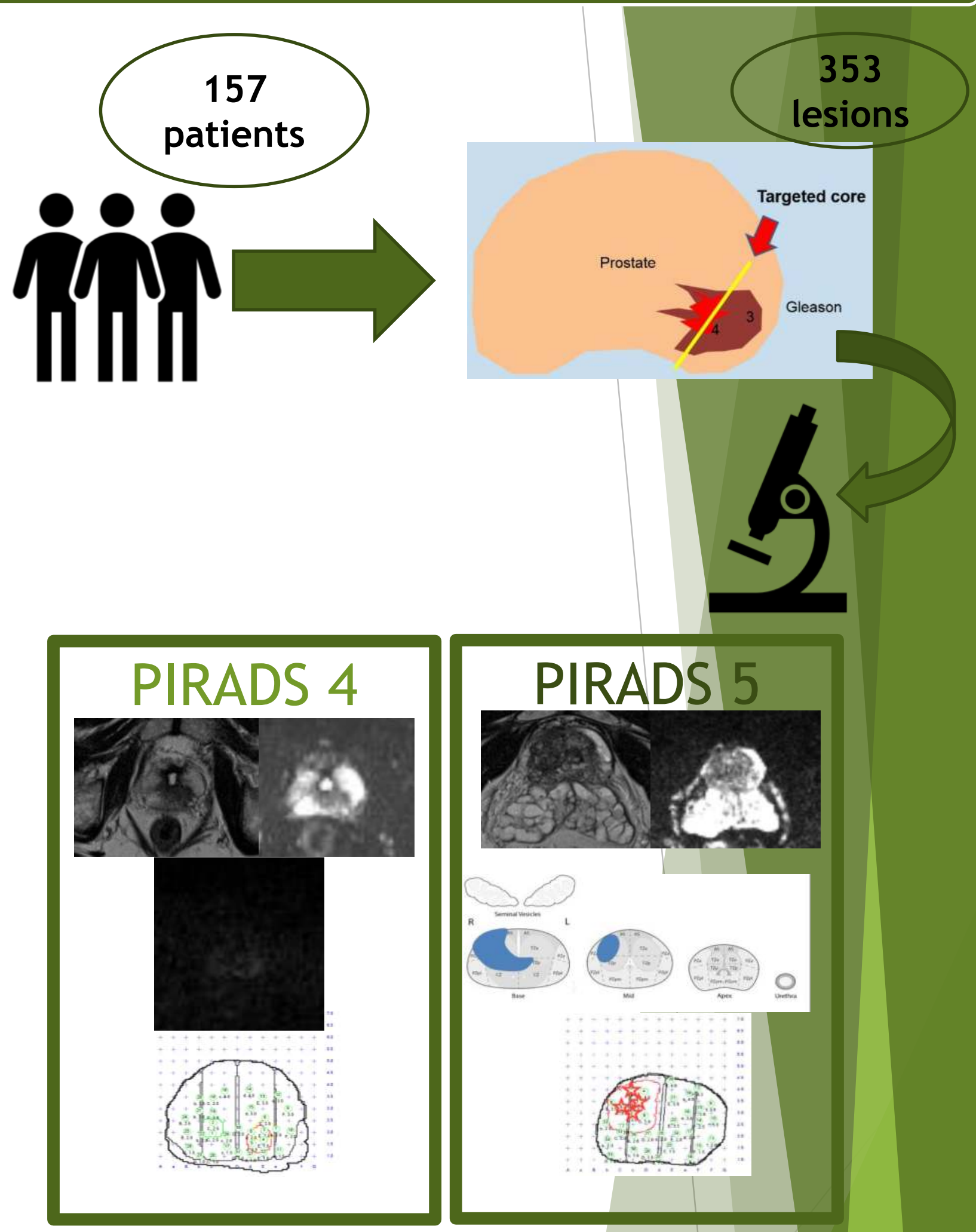

Positive predictive value (by PIRADS)

\begin{tabular}{|c|c|}
\hline PI-RADS 3 & $11 \%$ \\
\hline PI-RADS 4 & $77 \%$ \\
\hline PI-RADS 5 & $97 \%$ \\
\hline
\end{tabular}

\section{DISCUSSION/CONCLUSION:}

- This study demonstrated a correlation between detection of prostate cancer and PIRADS score in patients undergoing fusion biopsy.

- The results obtained were in agreement with the existing literature 